\title{
Prevention of Risk and Complications Associated with Heart Catheterization
}

\author{
Mary W Mwaura*, Sharon L Van Sell and Catherine Bailey \\ The Houston J and Florence a Doswell College of Nursing, USA \\ *Corresponding author: Mary W Mwaura, The Houston J and Florence a Doswell College of Nursing, USA
}

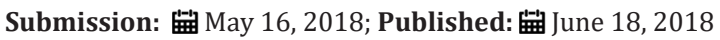

\begin{abstract}
Nurses play a dynamic role, in the interdisciplinary team within the health care arena. The purpose of this paper is to demonstrate the nurse's role in the prevention of risks and access site complications following heart catheterization using complexity integration nursing theory. The initiative could save our nation tax dollars towards health care by reducing length of hospital stay, loss of work days and reduce exorbitant costs related to the management of access site complications following percutaneous coronary intervention
\end{abstract}

Keywords: Percutaneous coronary artery; Heart catheterization; Wound care

Abbreviations: MI: Myocardial Infarction; ACS: Acute Coronary Syndrome; PCI: Percutaneous Coronary Syndrome; CINT: Complexity Integration Nursing Theory; STEMI- ST Elevation Myocardial Infarction; NSTEMI: Non ST Elevation Myocardial Infarction

\section{Problem Identification}

Nursing profession provides leadership within the health care industry. It cannot be overemphasized, that nurses contribute significantly in the prevention of risks and complications associated with the heart catheterization. In my experience and observation, heart catheterization ranks highest among the procedures being performed in the critical care unit. This is linked to unhealthy lifestyles, for example increased prevalence of smoking habits and sedentary lifestyles that contribute to adverse changes within the cardiovascular system. The indications for this common procedure include but are not limited to: acute coronary syndromes (ACS) such as unstable angina, ST elevation myocardial infarction (STEMI), non-ST elevation myocardial infarction (NSTEMI) and non ACS such as peripheral vascular disease. Heart catheterization, involves accessing the cardiovascular system via femoral artery and radial artery for diagnostic and angioplasty purposes. Acute coronary syndromes are a significant cause of hospitalization and mortality [1]. Angioplasty is comprised of, placing drug eluting stents (DES), bare metal stents (BMS), both rotational and directional art herectomy, and cutting balloon. In my own observation and experience, the care of the access site is not standardized and varies with the cardiologists. A need was identified to develop a nursing evidence-based best practice protocol, regarding complications associated with the heart catheterization access site, and also the global care of the population undergoing heart catheterization. The nursing based protocol, is the identification of hematoma and the management. Complications from the heart catheterization access sites frequently result in repeated hospitalization.

In an effort to provide a standard of care for the management of heart catheterization patients, the American Heart Association (AHA), American College of Cardiology Foundation (ACCF), and the Society for Cardiovascular and Angiography Interventions (SCAI) have developed guidelines for the care of heart catheterization patients [2], which included strategies to prevent and provide pain control, to prevent arrhythmias and stroke, and to provide cardiac rehabilitation. The following account is a summary of the practice guideline First and foremost the client needs to provide an informed consent since heart catheterization is ranked among the invasive procedures [3].

In addition, it is important to maintain fidelity by making it clear that the heart catheterization procedure has remarkable limitations and an emergency coronary artery bypass graft could be necessary. There is need to emphasize also the possibility for transfusion of blood and blood products as deemed necessary. The patient needs to be aware that the anesthetics could be changed without further explanation. The catheterization lab must adhere to the national procedures to ensure radiation safety. There is need to carry out pre-procedure hydration to keep at bay contrast induced acute kidney injury (AKI) [4]. If the patient has had an allergy to the contrast, great measures must be taken to administer steroid and antihistamine [2]. Patients with a history of shellfish 
or seafood allergy do not benefit from anaphylactic prophylaxis for contrast reaction. Administration of high dose statin is reasonable before percutaneous coronary intervention (PCI).Administration of $\mathrm{N}$-acetyl-L-cysteine is not beneficial for the prevention of contrastinduced acute kidney injury [4]. The diligence in monitoring cardiac markers creatinine kinase-MB and troponin could be helpful [2].

The following account is a continued summary of the practice guidelines. Use of radial access can be useful in significantly reducing the access site complication [5]. Primary PCI should be performed within 12 hours of onset but within 90 min of arrival to facility with PCI capability but 120min allowed for a facility without PCI capability. The accredited facility should have more than 400 PCI procedures annually. The provider should be a certified cardiology intervention by the internal medicine board and should have carried an annual volume of at least 75 procedures. Hemodynamic support device need to be used for patients in cardiogenic shock. Aspirin and P2Y12 inhibitor like clopidogrel should be administered immediately post procedure. Aspirin is then continued at a lower dose [81mg] indefinitely. On the other hand, cp2Y12 inhibitor should be administered for 1 month in non ACS but for one year in ACS PCI (DES and BMS). It is reasonable to administer a high dose statin before heart catheterization. The use of proton pump inhibitor is indicated, if the patient has had a history of gastrointestinal bleeding [6]. There is need also to continually monitor patient for gastro-intestinal bleeding following ACS [7]. Since the benefit of anticoagulation outweighs that of bleeding, it is vital to ensure the client receives at least 2 doses of therapeutic unfractioned heparin (UFH). Moreover, it is imperative to administer 1 dose of UFH during the procedure [2].

A preliminary review of the literature suggested that researchers have been studying various strategies to overcome the risk of morbidity and mortality in patients who have had a heart catheterization. There is a need to critically analyze the current Finding

Table 1: Critical analysis of quantitative research articles. research that has been shown to support the care of patients who have had a heart catheterization. Thus, the purpose of this paper is to develop an evidence based protocol for the role of the nurses in prevention of risks and complications following heart catheterization

\section{Literature Review}

A summary of the literature review to support the topic of Prevention of risk and complications related to Heart Catheterization. First the literature review process will be described followed by the key literature review findings.

\section{Search Process}

A comprehensive search was conducted by accessing Texas Woman's University databases including the Cochrane library which retrieves studies from Cochrane central register for controlled trials (CENTRAL) 1999 to January 2014, Medline, and CINAHL complete. Keywords used are percutaneous coronary intervention (PCI) and heart catheterization. The search was limited to articles published from 2009-2014 and in English. Use of the keyword PCI yielded 262 results. I also did a preliminary search in proQuest nursing and allied health source database using the keywords heart catheterization for the last 5 years and found 2746 articles. I then delimited by full text, "research" and "access complications.

This effort generated 593 articles. Articles that include cost utility analysis of clopidogrel, behavioral intervention for smoking cessation, smoking cessation and weight gain in patients with cardiovascular disease or risk factor, angioplasty and stenting safe in smaller hospitals, renal function, in-hospital events in ACS and the risks associated with antithrombotic/antiplatelet therapy were found relevant to this study. The theoretical foundation was the complexity integration nursing theory (CINT) which guided in construction of a decision tree.

\begin{tabular}{|c|c|c|c|c|c|}
\hline 1. Title & $\begin{array}{l}\text { 5. Patient } \\
\text { Population }\end{array}$ & 7. Intervention of Interest & \multirow{4}{*}{$\begin{array}{c}10 . \\
\text { Comparison } \\
\text { of Interest }\end{array}$} & 11. Outcome of Interest & 14. Strengths \\
\hline $\begin{array}{l}\text { 2. Principal } \\
\text { Investigator/ } \\
\text { First Author }\end{array}$ & \multirow{3}{*}{ 6. Sample Size } & $\begin{array}{l}\text { 8. Design (Experiment, } \\
\text { observation, etc.) [1] }\end{array}$ & & 12. Results of Study & \multirow{3}{*}{ 15. Limitations } \\
\hline 3. Date & & \multirow{2}{*}{ 9. Level of Evidence (I-VII) [2] } & & \multirow{2}{*}{ 13. Conclusion } & \\
\hline 4. Country & & & & & \\
\hline $\begin{array}{l}\text { 1. A cost-utility } \\
\text { analysis of } \\
\text { clopidogrel in } \\
\text { patients with } \\
\text { ST elevation } \\
\text { acute coronary } \\
\text { syndromes in UK. }\end{array}$ & $\begin{array}{c}\text { 5.Patients } \\
\text { diagnosed with } \\
\text { STEMI }\end{array}$ & $\begin{array}{l}\text { 7. Administration of Clopidogrel } \\
\text { in addition to standard therapy. }\end{array}$ & \multirow[t]{4}{*}{$\begin{array}{l}\text { 10. Standard } \\
\text { therapy only }\end{array}$} & $\begin{array}{l}\text { 11. Value on incremental cost per } \\
\text { Quality adjusted life year (QLY) } \\
\text { ratio (ICER) less than } \$ 2500 \text { for } \\
1 \text { month and less than } \$ 4000 \text { per } \\
\text { year. }\end{array}$ & $\begin{array}{l}\text { 14. Heterogeneous } \\
\text { sample }\end{array}$ \\
\hline $\begin{array}{l}\text { 2.Jonathan } \\
\text { Karnon }\end{array}$ & \multirow{3}{*}{6.1000} & 8. Randomized clinical trial. & & $\begin{array}{l}\text { 12. ICER for } 1 \text { month } \$ 1857 \text {; for } 1 \\
\text { year } \$ 2925\end{array}$ & \multirow{3}{*}{$\begin{array}{l}\text { 15. Uncertain of the } \\
\text { parameters used in the } \\
\text { Markov model }\end{array}$} \\
\hline 3.201 & & \multirow{2}{*}{ 9. II } & & 13. Use of Clopidogrel in STEMI is & \\
\hline 4.UK & & & & cost effective. & \\
\hline
\end{tabular}




\begin{tabular}{|c|c|c|c|c|c|}
\hline $\begin{array}{l}\text { 1.Smoking } \\
\text { cessation and } \\
\text { weight gain } \\
\text { patients in } \\
\text { patients with } \\
\text { cardiovascular } \\
\text { disease or risk } \\
\text { factor }\end{array}$ & $\begin{array}{l}\text { 5. Smokers } \\
\text { with } \\
\text { cardiovascular } \\
\text { diseases or } \\
\text { risk-factor }\end{array}$ & $\begin{array}{l}\text { 7. Weight control } \\
\text { component } \\
\text { in addition to } \\
\text { smoking cessation } \\
\text { program }\end{array}$ & $\begin{array}{l}\text { 10. Smoking } \\
\text { cessation } \\
\text { program } \\
\text { without }\end{array}$ & 11.Score on Fagerstrom and OR & 14. Large sample \\
\hline 2. Jacqueline Issa & \multirow{3}{*}{6.1053} & $\begin{array}{l}\text { 8. Random clinical } \\
\text { trials }\end{array}$ & component & \multirow{3}{*}{$\begin{array}{l}\text { 12. OR 2.41,P }>0.01 \text {; Fagerstrom } \\
\text { 1.23, } \mathrm{P}>0.01\end{array}$} & \multirow{3}{*}{$\begin{array}{l}\text { 15. Homogenous sample; Failed to use } \\
\text { anthropometric measures }\end{array}$} \\
\hline 3.2014 & & \multirow{2}{*}{ 9.II } & & & \\
\hline 4.Brazil & & & & & \\
\hline $\begin{array}{l}\text { 1. Preventionof } \\
\text { contrast-induced } \\
\text { acute kidney } \\
\text { injury }\end{array}$ & $\begin{array}{l}\text { 5. Patients } \\
\text { with Chronic } \\
\text { renal } \\
\text { insufficiency } \\
\text { undergoing } \\
\text { elective heart } \\
\text { catheterization }\end{array}$ & $\begin{array}{l}\text { 7. Administration } \\
\text { of either } \mathrm{N} \text {-acetyl } \\
\text { cysteine or } \\
\text { ascorbic acid }\end{array}$ & $\begin{array}{c}10 . \\
\text { Administration } \\
\text { of Placebo }\end{array}$ & $\begin{array}{l}\text { 11. Prevent contrast induced } \\
\text { nephropathy (CIN) }\end{array}$ & $\begin{array}{l}\text { 14. Type II error; single center } \\
\text { experience }\end{array}$ \\
\hline 2. Martin Brueck & \multirow{3}{*}{6.520} & $\begin{array}{l}\text { 8. Random } \\
\text { controlled trial. }\end{array}$ & & $\begin{array}{l}\text { 12. Failed to demonstrate the } \\
\text { usefulness of } \mathrm{N} \text {-acetyl cysteine } \\
\text { and ascorbic acid in preventing } \\
\text { CIN. }\end{array}$ & \multirow{3}{*}{ 15. Supported earlier similar findings } \\
\hline 3. 2013 & & & & 13 There is no benefit & \\
\hline 4. Germany & & 9. II & & $\begin{array}{l}\text { cysteine and ascorbic to } \\
\text { patients with underlying } \\
\text { chronic renal insufficiency to } \\
\text { prevent CIN }\end{array}$ & \\
\hline $\begin{array}{l}\text { 1. Routine early } \\
\text { angioplasty after } \\
\text { fibrinolysis in } \\
\text { acute myocardial } \\
\text { infarction }\end{array}$ & $\begin{array}{l}\text { 5. Patients } \\
\text { with STEMI } \\
\text { receiving } \\
\text { fibrinolysis } \\
\text { therapy }\end{array}$ & $\begin{array}{l}\text { 7. PCI within } \\
6 \text { hours of } \\
\text { fibrinolysis }\end{array}$ & \multirow{4}{*}{$\begin{array}{l}\text { 10. Standard } \\
\text { therapy }\end{array}$} & $\begin{array}{l}\text { 11. Significant fewer ischemic } \\
\text { complications }\end{array}$ & 14. Large sample \\
\hline 2. Warren Cantor & \multirow{3}{*}{6.1059} & $\begin{array}{l}\text { 8. Random clinical } \\
\text { trials }\end{array}$ & & $\begin{array}{l}\text { 12. Decreased rates of coronary } \\
\text { artery bypass surgery }\end{array}$ & \multirow{3}{*}{ 15. Homogenous sample } \\
\hline 3. 2009 . & & \multirow{2}{*}{ 9. II } & & \multirow{2}{*}{$\begin{array}{l}\text { 13. There is lower mortality } \\
\text { and reinfarction with routine } \\
\text { early PCI after fibrinolysis }\end{array}$} & \\
\hline 4. Canada & & & & & \\
\hline $\begin{array}{l}\text { 1. Renalfunction } \\
\text { and in-hospital } \\
\text { events in ACS }\end{array}$ & $\begin{array}{l}\text { 5. Consecutive } \\
\text { MI patients } \\
\text { with available } \\
\text { creatinine }\end{array}$ & 7. None & \multirow{4}{*}{ 10. none } & \multirow{4}{*}{$\begin{array}{l}\text { 13. Renal insufficiency } \\
\text { influences the presentation } \\
\text { and reduces the likelihood of } \\
\text { receiving treatment according } \\
\text { to current guidelines }\end{array}$} & \multirow{4}{*}{ 14.large sample } \\
\hline 2. Szummer & \multirow{3}{*}{6.57477} & 8. observation & & & \\
\hline 3.2009 & & & & & \\
\hline 4. Sweden & & & & & \\
\hline
\end{tabular}




\begin{tabular}{|c|c|c|c|c|c|}
\hline $\begin{array}{l}\text { 1. Major adverse } \\
\text { cardiac events } \\
\text { among post } \\
\text { percutaneous } \\
\text { coronary } \\
\text { intervention } \\
\text { patients on } \\
\text { clopidogrel and } \\
\text { proton pump } \\
\text { inhibitors }\end{array}$ & $\begin{array}{l}\text { 5. Post PCI } \\
\text { patients }\end{array}$ & $\begin{array}{l}\text { 7. Clopidogrel and } \\
\text { PPI therapy }\end{array}$ & \multirow[t]{4}{*}{$\begin{array}{l}\text { 10. Clopidogrel } \\
\text { alone }\end{array}$} & 11. Prevent PCI complications & 14. Large sample \\
\hline 2. Ching & \multirow{3}{*}{ 6. 3,287} & $\begin{array}{l}\text { 8. Non- } \\
\text { experimental }\end{array}$ & & & \multirow{3}{*}{$\begin{array}{l}\text { 15.Genetic testing for CYP2C19 } \\
\text { deficiency not available }\end{array}$} \\
\hline 3. 2013 & & \multirow{2}{*}{ 9. Level IV } & & $\begin{array}{l}\text { 12. Adverse events occurred in } \\
\text { PPI group }\end{array}$ & \\
\hline 4. USA & & & & & \\
\hline $\begin{array}{l}1 . \\
\text { Gastrointestinal } \\
\text { bleeding in } \\
\text { patients with } \\
\text { acute coronary } \\
\text { syndromes (ACS) }\end{array}$ & $\begin{array}{l}\text { 5. Patients } \\
\text { with ACS }\end{array}$ & $\begin{array}{c}7 . \\
\text { Antithrombotic/ } \\
\text { antiplatelet }\end{array}$ & \multirow{3}{*}{ 10. none } & $\begin{array}{l}\text { 11. Prevent complication post } \\
\text { ACS }\end{array}$ & \multirow{3}{*}{ 14. Large heterogeneous sample } \\
\hline 2. Nikolsky & \multirow{2}{*}{$6.13,819$} & 8. Experimental & & $\begin{array}{l}\text { 12. Gastrointestinal bleeding) } \\
\text { GIB occurred in } 178 \text { patients }\end{array}$ & \\
\hline 3. 2009 & & 9. I & & $\begin{array}{l}\text { 13. GIB is a serious condition } \\
\text { of scenario of ACS and } \\
\text { independently associated } \\
\text { with mortality and ischemic } \\
\text { complications }\end{array}$ & \\
\hline
\end{tabular}

Note: Instructions are for each of the main articles (at least five) in support your proposed evidence based practice intervention, provide as many of these 15 characteristics as possible.

A practice guideline: the 2011 ACCF, AHA and SCAI guidelines for percutaneous coronary artery interventions is located at the www.guideline.gov secure website. A critical analysis of articles supporting the evidence is presented in Table 1. A regional medical center's heart catheterization policy was retrieved. To further support the role of nursing profession in prevention of risk and complication following heart catheterization, a right catheterization protocol was retrieved from institute with magnet status. Seven articles were considered relevant to the purpose of this paper. Two of the articles were published in International Journal of Cardiology, one in Journal of Internal Medicine, one in the New England Journal of Medicine, and another one in Journal of Invasive cardiology. There were four randomized clinical trials that focused on cost utility analysis of clopidogrel use in ACS, reduction of ACS risk by smoking cessation and prevention of Contrast induced nephropathy. There were two observational studies that focused on renal function and in hospital events in ACS and effect of concomitant administration of clopidogrel and proton pump inhibitor. There was a comprehensive review by Dandekar et al. [5] describing various complications following PCI which include but are not limited to:

A. Radial artery spasm which can be prevented by administration calcium channel blocker (verapamil) and nitrate cocktail.

B. Radial artery occlusion which can be prevented by patent hemostasis. The pressure applied to compress the access should not exceed $15 \mathrm{mmhg}$ of the systolic blood pressure. Also adequate anticoagulation should be administered to prevent radial artery thrombi.

\section{Hematoma formation}

D. It is immediately clinically apparent when transracial approach is utilized due to the superficial nature of the radial artery [5]. See Figure 1 for classification of hematoma and the recommended treatment. 


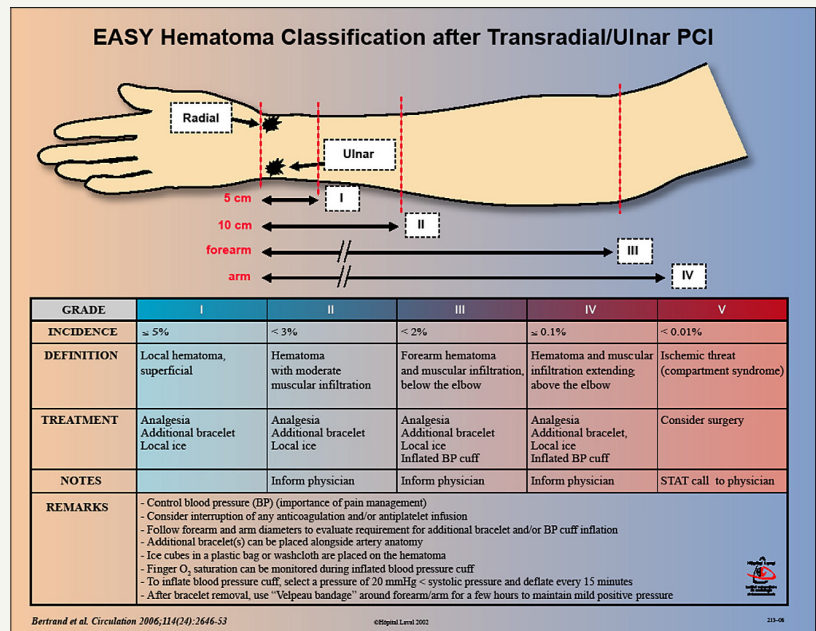

Figure 1: Recommended classification and management of hematoma [5].

E. Other rare complications include pseudoaneurysm, radial artery end arterectomy and perforation.

\section{Critical Analysis and Evaluation of Literature}

Critical analysis and evaluation of the literature are reflected in Table 1. The most salient to the proposed protocol is the cost utility analysis of clopidogrel in patients with ST elevation ACS in UK. The notion that no human being should have to choose between buying either essential commodities or maintenance medication following PCI sits at the crux of the study. Karnon et al. [1] conducted a nonrandomized clinical trial that focused on prevention of new MI, and stroke following PCI by using either Clopidogrel in combination with standard therapy or standard therapy alone. The study yielded level II of evidence as presented in the Evidence Hierarchy. The initial dose of Clopidogrel600mg must be administered immediately following PCI. The Clopidogrel 75mg should be administered for one year in combination with the standard therapy.

\section{Decision Tree}

There is increasing indication to advocate for the integration of the PCI guidelines to ensure optimal care to the patients undergoing heart catheterization. The nurse must realize that PCI is performed as an emergency procedure if the patient has STEMI. A quick focused assessment should be carried out to help determine diagnosis and to facilitate PCI within 90 minutes of arrival to emergency room. The assessment includes vital signs, EKG, telemetry monitoring and cardiac panel monitoring. An informed consent is obtained since heart catheterization is an invasive procedure. The catheterization team should be notified in timely manner.

CINT socializes nurses by decoding the unconscious and promoting meaningful interconnectedness with others [8]. The policies developed from the practice guideline following PCI should be used at all levels of care of the patient who has undergone PCI. The nurse not only needs to advocate for the patient in the health care arena but also safely administer the prescribed medication, teach the patient on clopidogrel-indications, and side-effects. The patient need to be connected with resources to ensure ample supply of clopidogrel and the standard medications needed following PCI.
It is imperative that all the guidelines to prevent access site complications are closely adhered to. It cannot be overemphasized that the patient needs to stay calm during the procedures to avoid multiple entries that could lead to radial artery spasm. In addition, the nurse ensures appropriate sizes of the hydrophilic sheaths are available in order to protect the patients from endarterectomy of the radial artery The staff member removing the sheath, must be highly skilled and demonstrate gentleness to further prevent eversion. The preferred approach should be the radial approach [5]. Transradial (TR) band dressing should be left in place, for three hours, by inflating with air pressure not greater than $15 \mathrm{~mm}$ hg of the systolic blood pressure on achieving hemostasis. The TR band is then deflated 1 milliliter of air at a time to half of the air content. The remaining air is left for an additional 15 minutes. If any bleeding is observed the air deflated is replaced. However if no bleeding is observed the remaining air should be deflated and pressure dressing left in place [9]. The formation of varying degrees of hematoma should be monitored and closely follow the recommendations in Figure 2. The following summary of the decision tree is a classic example how CINT can be utilized in the treatment of hematoma formation following PCI.

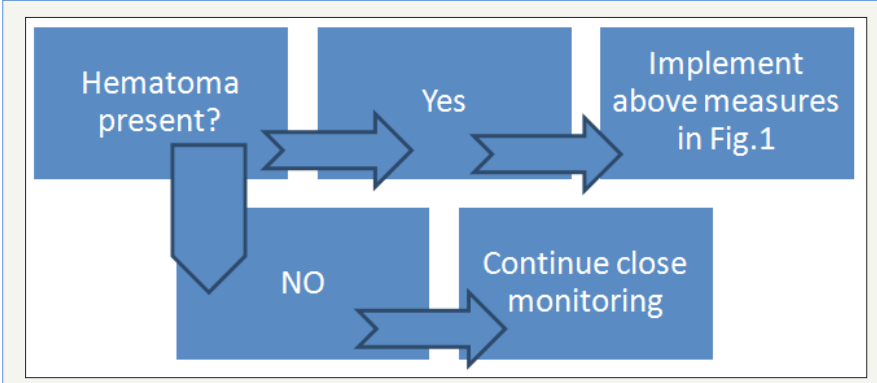

Figure 2: Hematoma management decision tree.

\section{Discussion}

According to the evidence hierarchy, the opinion of authorities and committee yields inferior evidence and is usually not standardized as compared to PCI practice guidelines [10]. The transfemoral approach is the most favored approach for heart 
catheterization access site. However the transradial approach result s in fewer complications such as bleeding [5]. The superficial nature of the radial artery enables immediate recognition of hematoma formation. Moreover varying measures can be utilized to greatly reduce the other complications related to the access site. This is reflected in the study findings that bleeding rates after PCI have been reduced with use of smaller sheaths, radial access, the administration of lower doses of anticoagulant and the elimination of post procedural heparin infusions [11]. The implementation of Evidence Based Practice will attract insurance coverage and collegial relationship within the interdisciplinary team. The critical care nurses are expected to develop assessment skills to help prevent complications following PCI. The protocol will help critical care nurses understand primary preventative measures to prevent complications related to ACS like smoking cessation [12].

Health care facilities utilizing this intervention can be expected to decrease in length of hospitalization because implementation of evidence base practice is positively correlated with the prevention of access site complications. The nurse is knowledgeable about the role of the members of the health care team and can prescribe the expected role in implementation of evidence based practice. This is evident in the right heart catheterization policy form a magnet status hospital [13]. It is interesting to note also the regional facility pre-heart catheterization orders [9]. Nursing is both an art and science. The nurse uses the nursing process- assessment, nursing, diagnosis, Plans, Implements and evaluates the patients care related to heart catheterization. The nurse educates the patient to report any pain, numbness and monitors oxygen saturation distal to the radial artery accessed. The nurse carries out the doctor's orders but ensures that the orders are congruent with best practices. In most instances the nurse requests the doctor to give orders because she is knowledgeable of what the patient needs. The role of CINT is to provide the theoretical framework of the purpose of the nursing profession in utilization of evidence based practice within the health care arena.

This study is limited due to homogenous nature of samples in the majority of the studies presented. The external validity must be investigated further and utilize the findings as the foundation of further research [14].

\section{References}

1. Karnon J, Holmes MW, Williams R, Bakhai A, Brennan A (2010) A cost-utility analysis of clopidogrel in patients with ST elevation acute coronary syndromes in the UK. Int J Cardiol 140(3): 315-322.

2. Levine GN, Bates ER, Blankenship JC, Bailey SR, Bittl JA, et al. (2011) 2011 ACCF/AHA/SCAI guideline for percutaneous coronary intervention a report of american college of cardiology/american heart association/ society of cardiovascular angiography interventions: a guideline for percutaneous coronary intervention. J Am Coll Cardiol 58(24): e44-e122.

3. Marjot, Thomas MB, Maruthappu M, Shalhoub J (2013) Checklists for invasive procedures. The New England Journal of Medicine 368(3): 293294.

4. Szummer K, Lundman P, Jacobson SH, Schön S, Lindbäck J, et al. (2010) Relation between renal function, presentation, use of therapies and in-hospital complications in acute coronary syndrome: Data from the SWEDEHEART register. J Intern Med 268(1): 40-49.

5. Dandekar VK, Vidovich MI, Shroff AR (2011) Complications of transradial Catheterization. Cardiovasc Revasc Med 13(1): 39-50.

6. Ching GG, Li D, Baker WL, Hohl PK, Mather JF, et al. (2012) Major adverse cardiac events among post percutaneous coronary intervention patients on clopidogrel and proton pump inhibitors. Connecticut Medicine 76(4): 205-211.

7. Nikolsky E, Stone GW, Kirtane AJ, Dangas GD, Lansky AJ, et al. (2009) Gastrointestinal bleeding in patients with acute coronary syndromes: Incidence, predictors, and clinical implications. J Am Coll Cardiol 54(14): 1293-302.

8. Van Sell SL, Kalofissudis IA (2010) Complexity integration nursing theory. ICU Web Journal, Athens, Greece.

9. Abilene Regional Medical Center (2013) Cardiac cath lab pre-procedural standing orders. Abilene regional medical center intranet, Texas, USA.

10. Polit DF, Beck TC (2012) Nursing Research: Generating and assessing evidence for nursing practice ( $9^{\text {th }}$ edn), Lippincott Williams \& Wilkins, New York, USA.

11. Warren, Fitchett D, Borgundvaag B, Ducas J, Heffernan M, et al. (2009) Routine early angioplasty after fibrinolysis for acute myocardial infarction. N Engl J Med 360(26): 2705-2718.

12. Issa JS, Santos PCJL, Vieira LP, Abe TO, Kuperszmidt CS, et al. (2014) Smoking cessation and weight gain in patients with cardiovascular disease or risk factor. International Journal of Cardiology 172(2): 485487.

13. Baylor All Saints Medical center at Fort Worth (2013) Policy name: Right heart Catheterization. Baylor University Medical Center, Texas, USA.

14. Bruek M, Cengiz H, Hoeltgen R, Wieczorek M, Boedeker RH, et al. (2013) Usefulness of $\mathrm{N}$-acetyl cysteine or ascorbic acid to prevent contrastinduced Acute kidney injury in patient undergoing elective cardiac catheterization. J Invasive Cardiol 25(11): 1047-1054.
Creative Commons Attribution 4.0 International License

For possible submissions Click Here

\section{Submit Article}

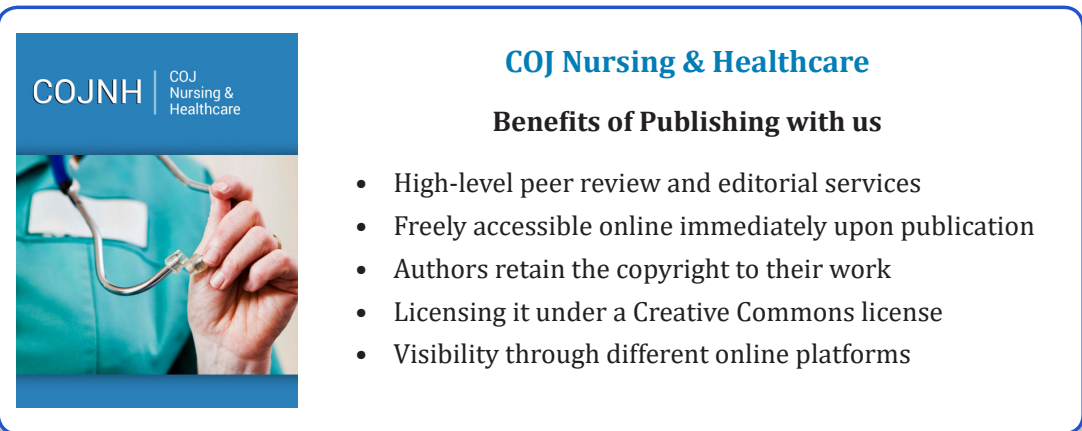

